\title{
Práticas de risco entre os jovens: estudo preliminar sobre condutas ordálicas
}

\author{
Patrícia Junqueira Grandino* \\ Universidade de São Paulo, Escola de Artes, Ciências e Humanidades. São Paulo, SP, Brasil
}

Resumo: 0 presente trabalho relata a discussão de uma pesquisa em andamento sobre o sentido das práticas de risco assumidas por jovens na transição para a vida adulta e resultados preliminares de um estudo piloto utilizando - Questionário de Funcionamento Ordálico. A partir da retomada do conceito de condutas ordálicas, procura-se aprofundar a análise de práticas de risco envolvendo jovens brasileiros como sintomas de um mal-estar que vivenciam na transição para a vida adulta. Realizou-se um experimento piloto com a aplicação de um questionário que avalia o funcionamento ordálico. A amostra inicial contou com 82 estudantes universitários, de ambos os sexos. Os resultados preliminares foram promissores na comparação dos quatro fatores por sexo dos sujeitos e na correlação com a idade. Avançar nessa perspectiva de investigação deve colaborar para o entendimento aprofundado dessas práticas, bem como para o desenvolvimento de ações preventivas e protetivas aos jovens.

Palavras-chave: práticas de risco, condutas ordálicas, juventudes.

\section{Introdução}

As questões relacionadas às violências praticadas por e contra adolescentes e jovens têm sido motivo de debate em diferentes campos do conhecimento e estão presentes na propositura de políticas públicas para essa faixa etária da população. São diversas as perspectivas de compreensão dessa temática e, no nosso entendimento, as abordagens tradicionais pecam por não reconhecer - ou desconsiderar - dimensões subjetivas de algumas das práticas juvenis. Desde meados da década de 1990, quando participamos de uma pesquisa sobre o tema da violência juvenil e entrevistamos alguns jovens que praticavam "surf ferroviário", despertamos nossa atenção para os sentidos pouco evidentes - e em geral desprezados no debate acadêmico - da motivação e complexidade de práticas transgressivas assumidas por adolescentes e jovens. Entendemos que é preciso avançar nas frentes de investigação e na construção de parâmetros conceituais que permitam uma compreensão mais acurada desses fenômenos. Consideramos, ainda, que as abordagens tradicionais apreendem parcialmente a complexidade ou estão fortemente marcadas por visões estereotipadas de juventude. Retomamos, há cerca de dois anos, o tema das práticas de risco reconhecendo nelas um sintoma do mal-estar dos jovens na transição para a vida adulta. Nesse percurso, identificamos alguns pesquisadores franceses que elaboraram um instrumento promissor para avançar nessa perspectiva de investigação. O presente trabalho, portanto, relata a discussão de uma pesquisa em andamento sobre 0 sentido das práticas de risco assumidas por jovens na transição para a vida adulta e resultados preliminares de um estudo

1 Trata-se de modalidade urbana, verificada em meados da década de 1990, hoje erradicada, nas quais jovens usuários dos trens urbanos executavam manobras semelhantes às do surf em cima das composições em movimento (ver Peralva, 2000).

* Endereço para correspondência: patjg@usp.br piloto utilizando o Questionário de Funcionamento Ordálico, que será detalhado adiante. Nossa expectativa, nesse sentido, é trabalhar nas próximas etapas por uma validação desse instrumento aplicado à realidade brasileira.

\section{Contexto histórico e desafios do marco legal}

Embora o Estatuto da Criança e do Adolescente (ECA) tenha sido promulgado em 1990, os desafios para reordenar políticas e garantir os direitos elencados no texto da Lei permanecem abertos.

Imerso em inúmeras críticas, o ECA, vale lembrar, não foi elaborado em gabinetes políticos. Antes, resultou de ampla mobilização social decorrente da retomada democrática brasileira na década de 1980 e do alinhamento a diversos documentos internacionais que versam sobre direitos de crianças e adolescentes, bem como na área do direito penal juvenil. Desse modo, trata-se de uma legislação consoante à constituição brasileira, notadamente em seu maior triunfo, que é o da garantia de direitos civis individuais a toda a população.

Trata o ECA, sobretudo, de uma formalização legal das mudanças paradigmáticas em torno da noção de infância e juventude na atualidade. Partindo do reconhecimento de transformações históricas que têm ampliado a compreensão sobre as características singulares dessa etapa do ciclo vital (Grandino, 1999, 2004) e considerando-se a aceleração das mudanças socioculturais promovidas pelo avanço tecnológico, crianças e adolescentes estão no centro da cena social. Sabe-se que a infância e a adolescência caracterizam-se por complexos processos de desenvolvimento e aprendizagem e que condições sociais, culturais e ambientais atuam diretamente na formação e desenvolvimento das potencialidades humanas. O cuidado amplo que deve ser prodigado pela família, pelo Estado e pela sociedade como um todo são decisivos para garantir a formação das novas gerações de cidadãos. Na esteira dessas 
transformações, igualmente a juventude, que coincide com parte da faixa etária compreendida pela adolescência, mas que a transcende, insere-se no mesmo debate e conta hoje com uma legislação específica ${ }^{2}$.

Como decorrência de ocuparem sua legítima condição de sujeitos de direitos e pela reordenação relacional que passa a vigorar entre as diferentes gerações, processam-se novas subjetividades. Assim, as relações entre adultos e as novas gerações exigem revisão dos modelos de interlocução. Das práticas tradicionais verticais e hierarquizadas dos relacionamentos entre adultos e crianças, adolescentes ou jovens, começam a surgir outras, de natureza mais horizontalizada e negociada, em que se exige que ambas as partes sejam concebidas como sujeitos de direitos. A maior simetria entre os diferentes sujeitos impõe crescentemente a vigência de categorias como o diálogo, a negociação e o convencimento. Os modelos tradicionais, marcados pela expectativa de obediência e pela punição perdem legitimidade e eficácia. É no cotidiano das relações, em diferentes contextos e papéis sociais, que a mudança paradigmática aqui apresentada se confronta com os modelos anteriores e se efetiva no embate entre novas modalidades de convivência.

O que assistimos hoje, no que tange às relações entre adultos, crianças, adolescentes e jovens, é resultado de um enorme paradoxo. Por um lado, as transformações macroestruturais observadas no mundo ampliaram a noção de sujeito de direitos, estendendo-a a pessoas em condições especiais de desenvolvimento. Gradativamente, elas passam a reivindicar o espaço que lhes foi conferido, em vez de passivamente aguardarem as ações do poder público. Trata-se de um ganho e uma conquista, na direção das aspirações das sociedades democráticas, e também no sentido do reconhecimento da singularidade do processo de desenvolvimento humano. Por outro lado, temos as práticas institucionais fortemente fixadas nos valores de disciplinarização, moralização e controle de crianças e adolescentes.

Como pano de fundo, encontramos os adultos, representantes e reprodutores dessa ordem, a imprimirem maior controle quanto mais as crianças, adolescentes ou jovens reais, diante deles, insistem em revelarem-se e revelá-lo a ele. Submergidos aos mesmos desafios impostos pela contemporaneidade, os adultos padecem das dificuldades para sustentarem-se na condição de sujeitos, já que as lógicas atuais operam pela dessubjetivação e precariedade da condição humana (Birman, 2007). A fluidez e fragmentação do mundo contemporâneo transforma o tornar-se adulto numa perspectiva pouco valorizada socialmente, impregnada de um imaginário nada atraente, como aponta Singly (2000). Para este autor, ser adulto passa a ser percebido negativamente quando a essa condição equivale uma noção de "terminar de crescer", "sem ter mais nada a descobrir no mundo nem sobre si mesmo" (Singly, 2000, p. 10).

Igualmente respondendo às lógicas contemporâneas de apelo ao consumo, ao imediatismo e ao novo, a noção de juventude é cobiçada por todos, quando imaginariamente

2 Trata-se do Estatuto da Juventude - Lei Federal 12.852, de agosto de 2013 ela equivale a uma condição de potência (e ato), alegria, beleza, falta de responsabilidade e inconsequência. Assim compreende-se, em parte, a resistência e o paradoxo de nossa realidade: por um lado, as novas gerações, vivendo e incorporando a noção de sujeitos de direitos - e reivindicando por eles - mesmo que em condições desestruturantes como são as de violência ou da assunção de práticas de risco; de outro lado, a liquidez do tecido social contemporâneo - conforme tipifica Bauman (2001) - e as consequências de assujeitamento impostas aos sujeitos exacerbam a insegurança e desamparo e o mundo adulto sente-se ameaçado pela nova geração.

Como efeito de algumas dessas características do mundo ocidental moderno, observamos que em nosso país o novo paradigma de atendimento regulamentado pelo ECA e sustentado na doutrina da proteção integral não conseguiu consolidar-se no conjunto de práticas educativas. $\mathrm{O}$ mundo adulto, via de regra hostil aos jovens, dificulta as formas de ingresso deles, seja no mundo do trabalho, no avanço da escolarização e nos demais âmbitos da construção de sua autonomia.

Com adultos assujeitados e desresponsabilizando-se pelo acolhimento, cuidado e educação das novas gerações, observamos no contexto nacional a sua persistência em práticas obsoletas que tentam confinar crianças, adolescentes e jovens àquele lugar de objeto da ação do adulto, que não existe mais. Os adultos e suas instituições estão confusos e a juventude, precariamente acolhida, expressa seu mal-estar de diversas maneiras, por exemplo, por meio de práticas socialmente condenáveis, como as condutas ordálicas, que trataremos nesse artigo.

As condições precárias de vida de nossos jovens revelam, por meio dos sintomas sociais produzidos por essas dissincronias, as angústias e reclamos dos sujeitos que se confrontam em busca de reconhecimento. $\mathrm{O}$ uso abusivo de drogas lícitas e ilícitas, por exemplo, pode indicar uma tentativa frustrada dos jovens de enfrentar tais adversidades ou o fracasso da tentativa de postergarem o tornarem-se adultos. Esse é o cenário onde vicejam as práticas de risco, sobretudo em sua modalidade ordálica.

\section{Noção do risco e condutas ordálicas}

O surgimento da noção do risco, segundo Spink (2001), data do século XVI e aparece como um dos resultados da possibilidade humana de pensar o futuro como algo a seu alcance, portanto passível de controle e previsão. É claro que a humanidade sempre esteve às voltas com perigos e ameaças, mas a compreensão anterior era percebida como azar/sorte, chance, perigo, fatalidade - todas elas referidas a uma dimensão exterior e transcendente ao sujeito, na direção da vontade divina e do destino.

A economia capitalista e suas novas formas de produção introduziram a noção de organização e planejamento diante do futuro, na perspectiva de torná-lo "controlável". Trata-se de um futuro pautado na "previdência", na habilidade de "ver de antemão", e a previsibilidade crescente 
ganhou estatuto de valor social e pessoal. Não obstante, o risco está presente em diferentes contextos: na economia, na educação, nos esportes, na vida cotidiana. Podemos dizer, de modo geral, que na atualidade a noção do risco pode ser percebida em duas direções.

Numa delas, congrega valores de audácia e coragem, de certa ironia diante do perigo, de desafio frente a obstáculos e na direção de ampliar conquistas. Em outra, ela remete a apelos de contenção, de adesão às normas vigentes, alimentadas por um sentimento de destruição - pessoal ou social - em caso de transgressão. Ela está presente, portanto, nas diretrizes moralizadoras em diversos discursos sociais, como o da saúde (não fume, não beba, faça exercícios), da educação (forme-se, estude, a única via de formação é a da escolarização), acenando com devir tenebroso em caso de desvio e transgressão. Essas formas atuais de disciplinarização são dirigidas especificamente ao indivíduo, que deve desempenhá-las pelo autocontrole, pela vigilância do estilo de vida e monitoração constante de indicadores de qualidade.

Sobre o risco interpretado como controle, podemos refletir que o estreitamento de vazão às expressões da vivência humana termina por asfixiar os sujeitos, esvaziá-los e preencher esses vazios com uma falta de sentido da vida. O indivíduo sempre está aquém dos cuidados que deveria manter sobre si mesmo. É possível compreender, desse modo, que o engajamento em atitudes de risco responde à busca por sentido para a existência. Assume a condição de ordálio: a busca de significado para a vida no enfrentamento da morte, dando chances iguais de dela escapar.

O termo "ordálio" remete a uma prova jurídica utilizada na Idade Média que designava o Julgamento de Deus. Tratava-se de uma prova reservada apenas para casos muito graves, em relação aos quais as demonstrações de culpabilidade restassem dúbias. Consistia, de modo geral, em uma provação submetida ao acusado, recorrendo a elementos naturais (em geral a água ou fogo), a fim de verificar sua inocência ou culpabilidade. Inspiradas no termo, as condutas ordálicas (G.R.E.C.O., 1994) são práticas assumidas por pessoas, sobretudo jovens, de caráter repetitivo e que comportam um risco mortal. Uma atividade na qual a vida corre perigo e cujo desfecho deve ser imprevisível, mas que tem como objetivo um teste, e não o suicídio. $O$ que subjaz a essas condutas é o apelo ao destino, à sorte, na tentativa de controlá-lo e, ao sobreviver, levando a vida ao limite, revalidá-la, provando seu direito a ela.

A perspectiva das condutas ordálicas praticadas por adolescentes e jovens nos permite pensar sobre o que alguns chamam de "formas corrompidas de assunção do risco" (Spink, 2001), no sentido de que, pouco mediadas, encaminham os sujeitos para a destruição, como nos casos de uso abusivo ou dependência de substâncias psicoativas, a formas irresponsáveis de condução de veículos, ao sexo desprotegido ou outras expressões, como o surf ferroviário ou a participação em grupos violentos dentro de torcidas organizadas de futebol. Formam um conjunto no qual, a despeito da precariedade da ação, desvelam sintomas do mal-estar de jovens impelidos a ingressar num mundo adulto hostil, nada atraente e tampouco acolhedor.

\section{Abordagem investigativa de condutas ordálicas}

De maneira geral, os interesses do Groupe de Recherche et Études sur les Conduites Ordaliques (GRECO) formado por psiquiatras, psicanalistas, pesquisadores e trabalhadores sociais de origem francesa recaem sobre as toxicomanias, a epidemia de AIDS e práticas sexuais inseguras, os esportes radicais e, mais recentemente, sobre os transtornos alimentares, como a bulimia e a anorexia. $\mathrm{O}$ olhar desses pesquisadores se volta para as práticas de risco como condutas ativas para as quais, a partir dos anos 1980, adotam a noção de ordálio como referência interpretativa.

$\mathrm{O}$ interesse que reuniu o grupo partiu de uma insatisfação com a visão tradicional de áreas da saúde sobre a toxicomania, interpretada usualmente como forma de suicídio escapista. Questionando a insuficiência das respostas dessa abordagem tradicional, o grupo buscou apontar para uma dimensão positiva da tomada de risco. Para eles, a características das pessoas que colocam em ato repetidas vezes aquilo que a sociedade tende a execrar - e que é percebido como destrutivo e assustador -, demanda um questionamento diverso. Um olhar mais acurado para essas pessoas permite reconhecer que há uma busca em curso: elas se lançam ao acaso e assumem riscos esperando sair vivos dessas provas. A busca revela-se na repetição da assunção do risco, que difere diametralmente da fuga e evitação de sofrimento. Aspira-se a um renascimento, a uma passagem, a uma condição melhor ou a outra dimensão de si mesmo. Nessa perspectiva, as práticas de risco de caráter ordálico ganham contornos de metáfora iniciática, notadamente para os jovens contemporâneos.

Desse modo, ao proibir o uso de um certo número de substâncias, a sociedade faz um dos meios privilegiados para os adolescentes se colocarem à prova: fumar um baseado torna-se sinal de desafio aos adultos, transgressão da lei, tomada de risco mínimo e geralmente busca de reconhecimento pelo grupo de pares. O uso do tabaco ou do álcool tem frequentemente o mesmo sentido, o primeiro cigarro ou a primeira bebedeira funciona um pouco como rito de passagem. Satisfações orais regressivas, estas condutas simbolizam também frequentemente a apropriação pelo sujeito de atributos dos adultos, potência viril, coragem, convivialidade etc. (G.R.E.C.O., 1994) ${ }^{3}$

Além da perspectiva iniciática, pode-se reconhecer nessas condutas ordálicas uma dimensão transgressiva. Como transgressão, o que se destaca é o questionamento à legitimidade da lei, quando as práticas de risco são

\footnotetext{
3 Tradução da autora.
} 
vividas como confronto às normas socialmente vigentes - por exemplo, se confrontadas com os discursos sobre saúde, juventude e a vida. Subjetivamente, as condutas ordálicas permitem reconhecer uma tentativa de dar sentido, de validar a própria existência e, em alguns aspectos, de buscar por justiça e reparação. Corroborando as análises do GRECO, consideramos essa perspectiva a que mais fortemente sinaliza o mal-estar da juventude diante de um mundo adulto hostil.

Os estudos conduzidos pelo grupo francês compreendem que os sujeitos que adotam tais condutas têm vivido situações de "privação de segurança ou de amor, como se tivessem tido o sentimento de que o mundo é injusto" (G.R.E.C.O., 1994). Seu comportamento de risco como transgressão poderia ser interpretado como revide a uma sociedade violadora, em dívida com eles, numa demanda pouco compreendida de reparação. Os estudos em tela ainda destacam que alguns sujeitos que praticam modalidades de risco - cuja ação implica a repetição da conduta, as provas perigosas e emocionantes - referem sentir-se "viciados" nesse tipo de conduta, que vem a constituir-se em certo estilo de vida "outsider". Os pesquisadores também alertam que, diante da constatação da dependência ao consumo de drogas, podem reaparecer mais violentamente práticas de risco, na tentativa do sujeito em retomar o controle de sua vida (G.R.E.C.O., 1994).

\section{0 instrumento de avaliação de potencial ordálico}

Dentre os pesquisadores dedicados ao estudo das condutas ordálicas, destacamos o trabalho de Cardénal, Sztulman, e Schmitt (2007a), que formularam um instrumento que permite verificar o potencial de conduta ordálica, que tem servido de parâmetro investigativo para estudos sobre toxicomanias e transtornos alimentares. Mais amplamente, a validação do instrumento permitiu verificar sua pertinência de aplicação também para sujeitos "normais", prestando-se, dessa maneira, a investigações mais amplas, de caráter preventivo, inclusive, dentro do qual inserimos nossa pesquisa.

\section{A adaptação do instrumento ao contexto brasileiro}

O questionário de Funcionamento Ordálico, formulado por Cardénal et al. (2007a), foi validado a partir de resultados obtidos sobre 826 sujeitos (402 homens e 426 mulheres), estudantes de diferentes campi da Universidade de Toulouse, com idade média de 21,13 anos. Os resultados auspiciosos apresentados pelo grupo de pesquisadores motivaram nossa iniciativa neste estudo exploratório. Para realizá-lo, fizemos uma adaptação do instrumento, com vistas a avaliar sua pertinência ao público brasileiro. Como piloto, aplicamos o instrumento em 82 sujeitos, estudantes de graduação da Escola de Artes, Ciências e Humanidades da Universidade de São Paulo.
O instrumento permite encontrar um eventual "funcionamento ordálico", ou seja, a propensão a desenvolver condutas ordálicas, pois o princípio do qual os autores partem é o de que se um sujeito desenvolve condutas ordálicas, ele possui uma base de "funcionamento ordálico" que subjaz a estas condutas. Para evidenciá-lo, os autores tomaram como referência as características que Valleur e Matysiak (citados por Cardénal, Apter, Sztulman, \& Schmitt, 2007b) identificaram numa pesquisa sobre o índice ordálico nas adições: a consciência dos sujeitos sobre o risco, o sentido do risco possivelmente mortal e não diferenciado, associado a uma percepção desse risco como prova positiva ou heroica, a coexistência de setores diferentes de tomada de risco como os riscos ligados à velocidade na condução de veículos e os riscos de overdoses no emprego de substâncias psicoativas; os acidentes físicos, as hospitalizações que são indicadores objetivos dessas condutas; a existência de uma dimensão consciente ou voluntaria de transgressão, senão de um engajamento no campo da delinquência; e a adesão a crenças "animistas", ou supersticiosas (reencarnação, espiritismo).

Foram, então, definidas quatro dimensões:

- A dimensão "tomada de risco" (TR): corresponde à propensão do sujeito a se engajar em atividades perigosas. Ela compreende diferentes setores de tomada de risco (atividades esportivas, conduta perigosa ao volante, não utilização de preservativos). Ela engloba também itens relativos aos acidentes, batidas e fraturas do sujeito. Enfim, a presença de certas características psicológicas pode determinar fortemente como a tomada de risco é avaliada. Por exemplo: a necessidade de se distinguir dos outros, a existência de uma rivalidade com os outros.

- A dimensão "visão positiva do risco"(VP): faz referência à visão, positiva ou negativa, que o sujeito tem na tomada de risco ou das pessoas que assumem riscos, assim como a função narcísica da tomada de risco (tanto para o sujeito como em relação aos outros);

- A dimensão "transgressiva" (DT): ela avalia, de um lado, a relação com a lei, com as regras, com as proibições, com a autoridade policial. Ela avalia também, por outro lado, a propensão do sujeito a assumir "riscos transgressivos" (uso de drogas, condutas arriscadas);

- A dimensão "crenças" (DCr): avalia as crenças do sujeito nos domínios da sorte, do azar, do destino, com a ideia de uma personificação destes como proteção. Mas ela se refere também à superstição, às crenças na vida após a morte, na reencarnação.

A descrição e características do instrumento pareceram bastante pertinentes, e a possibilidade de aplicá-lo em sujeitos "não patológicos" amplia os empregos 
possíveis do questionário, atendendo tanto à pesquisa quanto à definição de eventuais projetos de atenção direta à juventude.

\section{Análisedos resultados doestudo piloto-Questionário de Funcionamento Ordálico}

Como mencionado, procedemos a uma primeira tradução do artigo de Cardénal, et al. (2007a) e do instrumento por eles proposto e validado. Com algumas adaptações, replicamos o questionário em 82 sujeitos ( $57 \%$ do sexo masculino e $43 \%$ do sexo feminino), estudantes universitários matriculados em cursos de graduação na EACH nos períodos vespertino e noturno, com idade média entre 18 e 20 anos (70,9\%). A idade média do estudo piloto é, portanto, equivalente à amostra original ${ }^{4}$. Os resultados foram submetidos a uma análise descritiva dos dados por meio do programa Statistical Package for Social Scientists (SPSS). Alguns dados serão analisados pela Análise de variâncias e pela correlação de Pearson.

A versão adaptada constou de 68 afirmações para as quais cada sujeito deveria apontar seu grau de concordância ou discordância de acordo com as alternativas: Plenamente de acordo (PA - atribuído valor 1); Concordo parcialmente (CP - atribuído valor 2); Discordo parcialmente (DP - atribuído valor 3); Não concordo (NC - atribuído valor 4). Considerando os resultados e método de análise apresentados pelos autores de referência, procedemos à mesma classificação de dimensões para verificação dos resultados de funcionamento ordálico:

\section{Dimensão 1 - Tomada de risco (TR)}

Diz respeito ao engajamento em atividades perigosas (atividades esportivas, conduta perigosa ao volante, não utilização de preservativos, acidentes, batidas, fraturas, rivalidade e necessidade de se distinguir dos outros). No formulário, com as afirmações distribuídas aleatória e alternadamente, a dimensão da Tomada de Risco (TR) compõe um conjunto de 18 afirmações relacionadas a situações em que os sujeitos poderiam ou gostariam de se envolver.

De maneira geral, os resultados das afirmações relacionadas à dimensão de Tomada de Risco (TR) apontam que os sujeitos analisados demonstram uma percepção significativa de se sentir competindo e de ser desafiados. Percebe-se também interesse em experimentarem esportes de risco (surf, asa delta, mergulho submarino etc.), ou seja, riscos socialmente valorizados, mas baixa aderência a riscos relacionados a maiores perigos, como brincar com a morte, sexo sem proteção ou direção perigosa, riscos desvalorizados socialmente.

\section{Dimensão 2: Visão Positiva do Risco (VP)}

Nesse tópico, do total de afirmações apresentadas no instrumento, 16 afirmações são referentes à visão,

4 Embora a pesquisa coordenada por nós compreenda sujeitos entre $15 \mathrm{e}$ 24 anos, para esse estudo piloto definimos sujeitos com idade equivalente ao estudo original. positiva ou negativa, que o sujeito percebe sobre tomada de risco ou das pessoas que assumem riscos, assim como a função narcísica da tomada de risco (tanto para o sujeito como em relação aos outros).

Os resultados das respostas que os sujeitos apresentam sobre afirmações relacionadas à visão positiva ou negativa do risco sugere que, no conjunto, a amostra percebe situações de risco como moderadamente estimulantes, exceto em situações nas quais o risco signifique perigo à integridade deles. Nesse sentido, não revelam visão idealizada nem romantizada do risco. As respostas sugerem que os sujeitos têm percepção de si relativamente ponderada e prudente, mas consideram necessária alguma disposição para enfrentar os riscos a fim de superarem obstáculos e obterem maior reconhecimento social.

\section{Dimensão 3 - Transgressiva (DT)}

Avalia a relação com a lei, com as regras, com as proibições, com a autoridade policial. Ela avalia também, de um outro lado, a propensão do sujeito a assumir "riscos transgressivos" (uso de drogas, condutas arriscadas). Está presente no instrumento em 19 afirmações.

Os resultados indicam pouca aderência dos respondentes a práticas transgressivas. Segundo os resultados, os sujeitos investigados demonstram-se atentos às leis e regras vigentes em sociedade, não desrespeitam leis de trânsito e não referem satisfação nem curiosidade em práticas transgressivas como uso de drogas alucinógenas ou usualmente consideradas pesadas (crack, cocaína, LSD). Há alguma indicação de uso de maconha e valorização de posturas irreverentes. Indicam reconhecer e respeitar figuras de autoridade (policiais, chefes, professores).

\section{Dimensão 4 - Crenças (Crs)}

São 16 afirmações presentes no formulário adaptado que avaliam as crenças do sujeito nos domínios da sorte, do azar, do destino, com a ideia de uma personificação destes como proteção. Mas essa categoria se refere também à superstição, às crenças na vida após a morte e na reencarnação.

Os resultados sobre essa dimensão apontam para pouca convicção dos jovens participantes do estudo em crenças mágicas como superstições, sorte ou destino. Mais significativas são as respostas que se dirigem à convicção no livre-arbítrio e na capacidade do indivíduo em aproveitar oportunidades. Consideram-se afortunados, mas não demonstram contar com a sorte para alcançar objetivos. Cerca de $80 \%$ dos respondentes acredita plenamente, ou em parte, na existência de Deus.

\section{Análise de variâncias e correlações ${ }^{5}$}

\footnotetext{
5 Agradecemos à $\operatorname{Prof}^{\mathrm{a}} \mathrm{Dr}^{\mathrm{a}} \mathrm{Cristina}$ Landgraf Lee pelo auxílio na tabulação quantitativa dos dados.
} 
Problematizando alguns aspectos dos dados coletados, aplicamos a análise ANOVA (análise de variância), a fim de identificar se os dados apresentam diferenças significativas em relação de gênero (masculino, feminino) entre as quatro dimensões verificadas, conforme se observa na tabela abaixo:

Tabela 1

Valores do teste ANOVA para as 4 dimensões e gêneros

\begin{tabular}{ccccc}
\hline Dimensões & Significância & Sexo & Média & $\begin{array}{c}\text { Desvio } \\
\text { padrão }\end{array}$ \\
\hline $\begin{array}{c}\text { Tomada de } \\
\text { risco }\end{array}$ & $\begin{array}{c}\mathrm{F}(75,2)= \\
1,13 ; \mathrm{p}=0,32\end{array}$ & Masculino & 2,71 & 0,34 \\
Visão positiva & $\mathrm{F}(69,2)=$ & Masculino & 2,71 & 0,30 \\
do risco & 1,$67 ; \mathrm{p}=0,19$ & Feminino & 2,59 & 0,43 \\
Transgressiva & $\mathrm{F}(74,2)=$ & Masculino & 2,87 & 0,39 \\
& 2,$05 ; \mathrm{p}=0,13$ & Feminino & 2,73 & 0,38 \\
& & Masculino & 2,39 & 0,36 \\
Crenças & $\mathrm{F}(76,2)=$ & Ma & \\
& 4,$47 ; \mathrm{p}<0,05$ & Feminino & 2,58 & 0,50 \\
\hline
\end{tabular}

Fonte: elaboração própria

As três primeiras dimensões (TR, VP, DT) não apresentam significância com relação ao gênero, o que denota certa equidade nas respostas entre estudantes do sexo masculino e feminino.

A dimensão 4 (crenças), apresenta significância $(\mathrm{p}<0,05)$. Os dados indicam predominância de ceticismo no gênero masculino. $\mathrm{O}$ gênero feminino tende, portanto, a demonstrar maior tendência a crenças em superstições, na sorte, no destino e em vida após a morte.

Não encontramos significância na correlação de Pearson entre idade e as quatro somatórias. Porém, encontramos correlação positiva entre indivíduos de menor idade e as seguintes afirmações:

\section{Dimensão 1 - Tomada de Risco (TR)}

6 - Eu acho insensato pessoas que arriscam sua pele praticando esportes perigosos.

(valor de $\mathrm{P}=-0,25 ; \mathrm{p}<0,05$ )

21 - Uma vida calma e tranquila seria, para mim, muito chata.

(valor de $\mathrm{P}=0,28 ; \mathrm{p}<0,01$ )

28 - Eu gostaria de saltar de parapente ou asa delta. (valor de $\mathrm{P}=0,24 ; \mathrm{p}<0,05$ )

\section{Dimensão 2 - Visão Positiva do Risco (VP)}

22 - Eu admiro a coragem das pessoas que arriscam suas vidas em atividades perigosas.

(valor de $\mathrm{P}=0,25 ; \mathrm{p}<0,05$ )

68 - Eu considero as pessoas que jogam com a vida e a morte um pouco como heróis.

(valor de $\mathrm{P}=0,23 ; \mathrm{p}<0,05$ )

\section{Dimensão 3- Transgressiva (DT)}

17 - Estou sempre pronto a fazer algo que seja bom para mim, sem medir as consequências.

(valor de $\mathrm{P}=0,23 ; \mathrm{p}<0,05$ )

\section{Dimensão 4 - Crenças (Crs)}

4 - Eu penso que o destino é traçado por cada um de nós.

(valor de $\mathrm{P}=0,29 ; \mathrm{p}<0,05$ )

25 - A sorte me permite superar os limites e ir mais longe.

(valor de $\mathrm{P}=0,26 ; \mathrm{p}<0,05$ )

47 - De uma maneira geral, a sorte joga a meu favor. (valor de $\mathrm{P}=-0,28 ; \mathrm{p}<0,01$ )

Os dados acima corroboram outros indicados anteriormente. É interessante verificar que entre os mais jovens há maior disposição para enfrentar riscos e confiar na sorte. Conforme vimos, os sujeitos desta amostra consideram-se afortunados e demonstram admiração pelo risco no que ele tem de socialmente valorizado. Cabe ainda mencionar que, embora a afirmação "17 - Estou sempre pronto a fazer algo que seja bom para mim, sem medir as consequências" esteja incluída na dimensão transgressiva, ela parece melhor indicar uma postura competitiva presente e incentivada no mundo atual. A fronteira entre o lícito e a oportunidade perde clareza e os jovens veem-se chamados a ultrapassar limites sem necessariamente considerar as consequências para suas vidas e projetos futuros.

\section{Considerações finais}

Os resultados obtidos no estudo exploratório corroboram as expectativas de postura previstas entre jovens, considerando maior suscetibilidade ao pensamento mágico e maior apreço a práticas consideradas de risco. Entretanto, conforme vimos nos resultados, a amostra composta por estudantes universitários revela-se relativamente prudente e confiante em suas próprias competências. Isso, ainda que de maneira indireta, permite maior convicção nas hipóteses com as quais viemos trabalhando de que o ingresso num curso superior e a decorrente ampliação de projetos de futuro servem como parâmetros reguladores de inserção positiva no mundo adulto e de "imunização" frente a condutas ordálicas.

De todo modo, e sendo ainda possível avançar em análises sobre os resultados obtidos, consideramos procedente $o$ Questionário de Funcionamento Ordálico para o contexto e público jovem brasileiros. O instrumento utilizado no estudo piloto, adaptado do original em francês, deverá receber algumas adaptações de redação e, eventualmente, de redução no número de afirmações, de modo a garantir maior fiabilidade na aplicação junto a estudantes do ensino médio público.

Nossa expectativa é avançar na investigação sobre a assunção de práticas de risco, notadamente as de caráter 
ordálico como sintoma de um mal-estar na transição para a vida adulta, uma vez que os resultados obtidos no estudo piloto não permitem uma confirmação dessa hipótese.
Compreendemos ser necessária, ainda, a utilização de outros instrumentos metodológicos para incrementar a pesquisa e ampliar seu espectro de análise.

\section{Risk practices among the young people: Preliminary study on ordeals conducts}

Abstract: This paper reports the discussion of an ongoing study on the meaning of risk practices by young people in the transition to adulthood and preliminary results of a pilot study using a questionnaire about trial by ordeal function. Based on the return to the concept of trial by ordeal conducts, we seek to deepen the analysis of risk practices involving young Brazilians as symptoms of a malaise that they experience in the transition to adulthood. We conducted a pilot experiment with the application of a questionnaire that evaluates the trial by ordeal function. The initial sample included 82 university students of both sexes. The preliminary results were promising in the comparison of the four factors by sex of subjects and in correlation with age. To advance this research perspective, contributions should be made to the thorough understanding of these practices as well as to the development of preventive and protective actions for young people.

Keywords: risk practices, ordeals conducts, youths.

\section{Pratiques à risque chez les jeunes: une étude préliminaire sur les conduites ordaliques}

Résumé: Le présent travail rapporte la discussion d'une étude en cours sur la signification des pratiques à risque menées par les jeunes dans la transition à l'âge adulte et les résultats préliminaires d'une étude pilote lequel utilise le Questionnaire de Fonctionnement Ordalique. À partir de la reprise de la notion de conduites ordaliques, nous cherchons à approfondir l'analyse des pratiques à risque impliquant des jeunes brésiliens comme symptômes d'un malaise qu'ils expérimentent dans la transition à l'âge adulte. Nous avons effectué une expérience pilote avec la soumission d'un questionnaire qui évalue le fonctionnement ordalique. L'échantillon initial comprenait 82 étudiants des deux sexes. Les résultats préliminaires ont été prometteurs dans la comparaison des quatre facteurs par le sexe des sujets et dans la corrélation avec l'âge. Avancer dans cette perspective de recherche devrait contribuer à la compréhension approfondie de ces pratiques ainsi qu'au développement d'actions de prévention et de protection pour les jeunes.

Mots-clés: pratiques à risque, conduites ordaliques, jeunesses.

\section{Prácticas de riesgo entre los jóvenes: estudio preliminar sobre las conductas ordálicas}

Resumen: Este trabajo presenta la discusión de un estudio que se está llevando a cabo sobre el significado de las prácticas de riesgo realizadas por los jóvenes en la transición a la edad adulta y los resultados preliminares de un estudio piloto utilizando el Cuestionario de Funcionamiento Ordálico. Retomando el concepto de conductas ordálicas, se intenta profundizar en el análisis de prácticas de riesgo con jóvenes brasileños como síntomas de un malestar que experimentan en la transición a la edad adulta. Se ha llevado a cabo una experiencia piloto con la aplicación de un cuestionario que evalúa el funcionamiento ordálico. La muestra inicial contó con 82 estudiantes universitarios de ambos sexos. Los resultados preliminares resultaron prometedores en la comparación de los cuatro factores por sexo de los sujetos y la correlación con la edad. El avance en esta perspectiva de investigación deberá contribuir a la comprensión profunda de estas prácticas, así al desarrollo de acciones de prevención y protección para los jóvenes.

Palabras clave: prácticas de riesgo, conductas ordálicas, juventudes.

\section{Referências}

Bauman, Z. (2001). A modernidade líquida. Rio de Janeiro, RJ: Zahar.

Bauman, Z. (2011). Vida em fragmentos: sobre ética pósmoderna. Rio de Janeiro, RJ: Zahar.

Birman, J. (2006). Arquivos do mal-estar e da resistência. Rio de Janeiro, RJ: Civilização Brasileira.
Birman, J. (2007). Mal-estar na atualidade. Rio de Janeiro, RJ: Civilização Brasileira.

Camarano, A. A., Mello, J. L., Pasinato, M. T., \& Kanso, S. (2004). Caminhos para a vida adulta: as múltiplas trajetórias dos jovens brasileiros. Rio de Janeiro, RJ, IPEA.

Carcassonne, M., Servel, L., (2010). L.Actes éducatifs et 
de soins, entre éthique et gouvernance, Mis en ligne le 01 octobre 2010URL: http://revel.unice.fr/symposia/ actedusoin/index.html?id=305.

Cardénal, M., Sztulman, H., \& Schmitt, L. (2007a). Le questionnaire de fonctionnement ordalique (QFO): premiers éléments de validation et résultats préliminaires chez des toxicomanes et des anorexiques. Annales Médico-psychologiques, revue psychiatrique, 165(10), 703-713. Recuperado de http:// www.sciencedirect.com/science?_ob=ArticleURL\&_ udi=B6X0W-4HMNG5S-1\&_user=5674931\&_coverDate $=12 \% 2$ F 31\%2F 2007\&_rdoc $=1 \&$ fmt $=$ high \& orig $=$ search \&_sort $=$ d\&_docanchor $=\&$ view $=\mathrm{c} \&$ _ searchStrId=1361964617\&_rerunOrigin=scholar. google\&_acct $=$ C $000049650 \&$ \&ersion $=1 \&$ \&urlVersion $=0 \&$ \&userid $=5674931 \& \mathrm{md} 5=\mathrm{a} 7 \mathrm{de} 9 \mathrm{c} 097 \mathrm{be}-$ 4da09b36f55bd9eb9768f

Cardénal, M., Apter, M. J., Sztulman, H., \& Schmitt, L. (2007b). États métamotivationnels chez des toxicomanes et des anorexiques restrictives: similitudes et différences. Psychotropes, (13), 69-90. doi: 10.3917/psyt.132.0069.

Cury, M., Amaral e Silva, A. F., \& Mendez, E. G. (Coords.). (1992). Estatuto da criança e do adolescente comentado: comentários jurídicos e sociais. São Paulo, SP: Malheiros.

Delors, J. (2000). Educação: um tesouro a descobrir. São Paulo, SP: Cortez.

Demo, P. (2000). Ambivalências da sociedade da informação. Ciência da Informação, 29(2), 37-42. Disponível em http:// www.scielo.br/scielo.php?script=sci_arttext\&pid=S0100$19652000000200005 \& \operatorname{lng}=\mathrm{pt} \& \mathrm{nrm}=$ iso.

Enriquez, E. (1994a). O papel do sujeito humano na dinâmica social. In Levy, A., Nicolaï, A., Enriquez, E., Dubost, J., Psicossociologia: análise social e intervenção (pp. 2744). Petrópolis, RJ: Vozes.

Enriquez, E. (1994b). A interioridade está acabando? In Levy, A., Nicolaï, A., Enriquez, E., Dubost, J. Psicossociologia: análise social e intervenção (pp. 4560). Petrópolis, RJ: Vozes.
Grandino, P. J. (1999). O educador de rua e suas práticas educativas (Dissertação de Mestrado). Faculdade de Educação da Universidade de São Paulo.

Grandino, P. J. (2004). A dimensão relacional na Educação: experiência formativa com educadores sociais $e$ professores (Tese de Doutorado). Faculdade de Educação da Universidade de São Paulo.

G.R.E.C.O. (1994). Toxicomanie et Mort: Addictions et conduites de Risque -Rapport de Recherche. G.R.E.C.O. Groupe de recherche et détudes sur les conduites ordaliques (mimeo).

Kowarick, L. (2009). Viver em risco: sobre a vulnerabilidade socioeconômica e civil. São Paulo, SP: Ed.34.

Lebrun, J.P. (2008). A perversão comum: viver juntos sem outro. Rio de Janeiro, RJ: Campo Matêmico.

Peralva, A. T. (2000). Violência e democracia: o paradoxo brasileiro. São Paulo, SP: Paz e Terra.

Roman, M.D. (2009). Psicologia e adolescência encarcerada. São Paulo, SP: Ed. Unifesp.

Schilling, F. (2004). A sociedade da insegurança e a violência na escola. São Paulo, SP: Moderna.

Singly, F. (2000). Penser autrement la jeunesse. Lien Social et Politiques, (43), 9-21. Recuperado de http://id.erudit. org/iderudit/005086ar.

Spink, M. J. P. (2001). Tropics of risk discourse: riskadventure as a metaphor in late modernity. Cadernos de Saúde Pública, 17(6). Disponível em http://www. scielosp.org/scielo.php?script=sci_arttext\&pid=S0102$311 \mathrm{X} 2001000600002 \& \operatorname{lng}=\mathrm{en} \& \mathrm{nrm}=$ iso. doi: 10.1590 / S0102-311X2001000600002

Spink, M. J., \& Medrado, B. (2004). Produção de sentidos no cotidiano: uma abordagem teórico-metodológica para a análise das práticas discursivas. In M. J. Spink (Org.), Práticas discursivas e produção de Sentidos no Cotidiano: aproximações teóricas e metodológicas (pp. 41-62). São Paulo, SP: Cortez.
Recebido: 04/12/2013

Revisado: 17/03/2015 Aceito: 05/05/2015 